\title{
A matter of life and death: population mortality and football results
}

\section{W Kirkup, D W Merrick}

See end of article for authors' affiliations .....................

Correspondence to: Bill Kirkup, NHS Northern and Yorkshire, John Snow House, Durham University Science Park, Durham DHI 3YG, UK: Bill.Kirkup@doh.gsi.gov.uk

Accepted for publication 14 January 2003

\begin{abstract}
Objectives: To determine whether football results are associated with mortality from circulatory disease.

Design: Retrospective study, comparing mortality on days of football matches between 18 August 1994 and 28 December 1999 with the results of the football matches.

Setting: Newcastle and North Tyneside, Sunderland, Tees, and Leeds Health Authority areas of England.

Subjects: All persons resident in Newcastle and North Tyneside, Sunderland, Tees, and Leeds Health Authority areas of England.

Main outcome measures: Mortality attributable to acute myocardial infarction and stroke.

Results: On days when the local professional football team lost at home, mortality attributable to acute myocardial infarction and stroke increased significantly in men (relative risk 1.28, 95\% confidence intervals 1.11 to 1.47). No increase was observed in women.

Conclusions: Results achieved by the local professional football team are associated systematically with circulatory disease death rates over a five year period in men, but not women.
\end{abstract}

$\mathrm{T}$ he late Bill Shankly is said to have highlighted the significance of professional association football to many people in characteristically pithy terms.

\begin{abstract}
"Some people believe football is a matter of life and death. I'm very disappointed with that attitude. I can assure you it is much, much more important than that". '
\end{abstract}

Many football fans seem to share that view, particularly in much of Europe and South America. The combined annual income of English professional football clubs for the 1999/2000 season topped one billion pounds, ${ }^{2}$ reflecting the amount that the public is prepared to spend on watching the game, and supporting their club by buying branded merchandise such as replica shirts. The passion felt by supporters for their club is readily evident at first hand, on television, and in popular literature. $^{34}$

In 2000, Witte $e t \mathrm{al}^{5}$ published a result that indicated higher mortality among men in Holland associated with a football match lost on penalty kicks by the Dutch team. The finding was based on a single international match played in 1996, and did not adjust for differential mortality on different days of the week or months of the year. The authors suggested that the stress associated with important games may trigger acute myocardial infarction or stroke.

The factors that precipitate an acute event including sudden death in a person with coronary artery or cerebrovascular disease are much less well understood than the causes of the underlying disease. Yet understanding the nature of these triggers is also important to the development of public health programmes to tackle these significant causes of premature death and disability.

There is evidence that psychological and emotional stress can act as triggers for acute vascular disease and sudden death. ${ }^{6-8}$ Many football supporters informally report marked changes of mood depending on the result achieved by their club in any competitive match, which could trigger acute deaths from myocardial infarction and stroke. We investigated patterns of mortality in four populations in the north of Eng- land according to the results of all competitive games involving the major local football team over a five year period.

\section{METHODS}

We took the results of the 1094 first team competitive football matches played by Newcastle United FC, Sunderland AFC, Middlesbrough FC, and Leeds United FC between 18 August 1994 and 28 December 1999 from Rothmans Football Yearbook. ${ }^{9-14}$ For each team, match results were grouped as either a home defeat or any other combination of result and venue.

We examined the effect, using $t$ tests ${ }^{15}$ of home defeat on the mean number of deaths on match days from acute myocardial infarction (ICD9 410/ICD10 I21-22) or stroke (ICD9 430-438/ ICD10 I60-69) in the health authority area in which these clubs are based: Newcastle and North Tyneside, Sunderland, Tees, and Leeds Health Authorities respectively. Mortality data came from the Office for National Statistics. We compared the effect of home games (all results) against away games (all results), and we compared the effects of won, drawn and lost games, regardless of venue, on the mean number of male deaths from acute myocardial infarction and stroke.

We used Poisson regression ${ }^{16}$ to estimate for each health authority population and for all four combined the relative risk of dying from acute myocardial infarction or stroke on days when the local football team lost at home compared with days when any other result was achieved. Relative risks with 95\% confidence intervals (CIs) were estimated separately for men and women, and were adjusted for the covariates month of year and day of week.

We compared the mean number of deaths from acute myocardial infarction or stroke on days when teams lost at home with the mean number of male deaths from these causes on the preceding and following three days.

\section{RESULTS}

Table 1 shows the mean number of male and female deaths per match day from acute myocardial infarction or stroke when the local professional football team lost at home, compared 
Table 1 Average number of $\mathrm{AMl} /$ stroke deaths per match day

\begin{tabular}{|c|c|c|c|c|c|c|c|}
\hline \multirow[b]{2}{*}{ Health authority area } & \multirow[b]{2}{*}{$\begin{array}{l}\text { Match days lost at } \\
\text { home (other result) }\end{array}$} & \multicolumn{3}{|c|}{ Mean daily deaths (male) } & \multicolumn{3}{|c|}{ Mean daily deaths (female) } \\
\hline & & $\begin{array}{l}\text { Lost at } \\
\text { home }\end{array}$ & $\begin{array}{l}\text { Other } \\
\text { result/ } \\
\text { venue }\end{array}$ & $\begin{array}{l}\text { p Value } \\
\left(t \text { test }^{*}\right)\end{array}$ & $\begin{array}{l}\text { Lost at } \\
\text { home }\end{array}$ & $\begin{array}{l}\text { Other } \\
\text { result/ } \\
\text { venue }\end{array}$ & $\begin{array}{l}\text { p Value } \\
\left(t \text { test }^{*}\right)\end{array}$ \\
\hline Newcastle and North Tyneside & $24(255)$ & 1.92 & 1.47 & 0.10 & 1.79 & 1.85 & 0.84 \\
\hline Sunderland & $22(258)$ & 1.82 & 1.10 & 0.03 & 1.14 & 1.14 & 0.99 \\
\hline Tees & $23(253)$ & 2.43 & 1.99 & 0.22 & 2.26 & 2.05 & 0.56 \\
\hline Leeds & $31(228)$ & 2.52 & 2.27 & 0.43 & 2.65 & 2.51 & 0.64 \\
\hline Pooled areas & 100 (994) & 2.20 & 1.69 & 0.0015 & 2.02 & 1.87 & 0.33 \\
\hline
\end{tabular}

Table 2 Association of local professional football team losing at home with mortality from AMl and stroke

\begin{tabular}{|c|c|c|c|c|}
\hline \multirow[b]{2}{*}{ Health authority area } & \multicolumn{2}{|l|}{ Male } & \multicolumn{2}{|l|}{ Female } \\
\hline & $\begin{array}{l}\text { Relative risk } \\
(95 \% \mathrm{Cl})^{*}\end{array}$ & $\mathrm{p}$ Value & $\begin{array}{l}\text { Relative risk } \\
(95 \% \mathrm{Cl})^{*}\end{array}$ & $\mathrm{p}$ Value \\
\hline Newcastle and North Tyneside & $1.19(0.87$ to 1.63$)$ & 0.29 & $0.90(0.66$ to 1.25$)$ & 0.54 \\
\hline Sunderland & 1.63 (1.16 to 2.30$)$ & $<0.01$ & $0.93(0.61$ to 1.42$)$ & 0.74 \\
\hline Tees & $1.18(0.89$ to 1.56$)$ & 0.25 & $1.08(0.81$ to 1.45$)$ & 0.59 \\
\hline Leeds & $1.17(0.91$ to 1.51$)$ & 0.21 & $1.11(0.87$ to 1.41$)$ & 0.39 \\
\hline Pooled areas & $1.28(1.11$ to 1.47$)$ & $<0.001$ & $1.07(0.93$ to 1.24$)$ & 0.34 \\
\hline
\end{tabular}

*Relative risk of $\mathrm{AMI} /$ stroke on days when local professional football team lost at home compared with any other result, from Poisson regression adjusted for month of year and day of week. †Two tailed $t$ test of relative risk equal to zero.

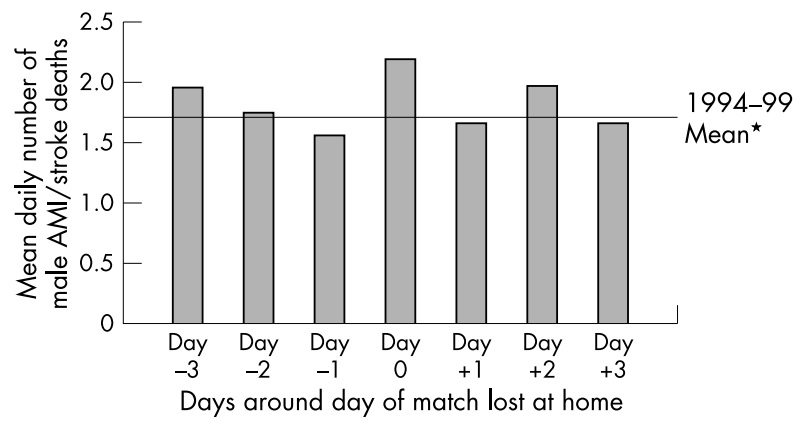

Figure 1 Mean number of male deaths on days before and after the day of matches lost at home by the local professional football team, pooled across four health authority areas. *Horizontal line represents mean daily number of deaths in the four health authority areas combined for the period 1994-99.

with days when the team played in a match with any other combination of result and venue. In each of the health authority areas, the average numbers of male deaths from acute myocardial infarction and stroke were greater on days when the local football team lost at home than on days when another result was achieved. In Sunderland Health Authority, stroke and acute myocardial infarction deaths increased by $66 \%$ in men on days when Sunderland AFC lost at home and this difference was significant.

Across the four areas combined (total resident population just over two million), male deaths increased by $30 \%$ when the local professional football team lost at home and this difference is highly unlikely to be attributable to chance alone. In contrast, the average numbers of female deaths were about the same on days when the local professional football team lost at home as on days when any other result was achieved.

The separate effects of home games and lost games on the rate of male mortality from acute myocardial infarction and stroke were much less powerful than the interactive effect of these two factors in combination. Across all four areas the mean daily number of male deaths from acute myocardial infarction and stroke increased very slightly, but not significantly, on days when the local professional football team played at

\section{Key points}

- The acute onset of coronary heart disease and cerebrovascular disease seems to be a "triggered event". There is evidence that psychological and emotional stress can act as triggers for acute vascular disease and sudden death.

- Witte et al found that a single important international football match, lost on penalties, was associated with increased cardiovascular mortality in Dutch men but not women.

- Over a five year period, male mortality from myocardial infarction and stroke was increased on days when the local professional football team lost at home in all four areas studied in the north of England.

- The effect was consistently seen in the areas studied, and was independent of day and month of the year. Mortality in women was unaffected.

- Trigger factors such as anger, frustration, and depression would merit further investigation.

home compared with when they played away (1.79 $v 1.69$, $p=0.23$ ). Across all four areas the mean daily number of male deaths from acute myocardial infarction and stroke increased slightly on days when the local professional football team lost compared with when they won $(1.84 v 1.67 \mathrm{p}=0.10)$.

Regression coefficients were adjusted for the covariates month of year and day of week to remove potential bias from this source. Table 2 shows the relative risks of death (and 95\% CIs) from acute myocardial infarction or stroke on days when the local professional football team lost at home compared with days when other results were achieved.

The regression results agree with the comparison of means. For men living in each of the four areas, the risk of death from acute myocardial infarction or stroke was greater on days when the local professional football team lost at home. On days when Sunderland AFC lost at home, male residents of Sunderland Health Authority were 1.63 times (95\% CI 1.16 to 2.3 ) more likely to die from these causes.

Across the four areas combined, male deaths from acute myocardial infarction or stroke increased by $28 \%$ (95\% CI $11 \%$ to $47 \%$ ) when the local professional football team lost at home. 
Figure 1 shows the mean number of male deaths from acute myocardial infarction and stroke across the four areas combined on days when the local professional football team lost at home and for the preceding and following three days. This is compared with the mean daily number of male deaths from acute myocardial infarction and stroke in the four health authority areas for the period 1994-99, which was 1.71 (95\% confidence interval 1.68 to 1.74 ).

On average, the number of male deaths from acute myocardial infarction and stroke was greater on days when the local professional football team lost at home than on the preceding and following three days. On average across the four areas combined, there were 0.54 fewer deaths on the day following football matches lost at home than on the day of football matches that were lost at home.

\section{DISCUSSION}

We have found an association between the outcome of football matches and deaths from circulatory disease, for men but not women. The association relates to all competitive games played by the local professional football team over a five year period. It extends the observation of Witte et al that male mortality increased after a single important international match involving Holland, and allows for possible distortion by the effects of differential death rates by day of the week and month of the year.

We selected the four health authority areas because of the characteristics of the local professional football club. They are the largest clubs in this health region, and the only ones that spent the whole study period within the top two levels of professional football. In each case, the great majority of the football support within the population covered by the local health authority goes to that club. The effect was seen consistently in each area studied and, although the observed increase achieved conventional statistical significance in only one area, the results in all areas combined were highly unlikely to be attributable to chance alone.

We took a home defeat as the critical outcome for local supporters, to be compared with other outcomes, for two reasons. Firstly, this is widely accepted to be the worst result for a team; supporters have lower expectations of their team's performance away from home, but are predisposed to anticipate a victory in a home game. Secondly, more people will have attended a home game and witnessed the defeat at first hand.

Cardiovascular death rates are known to vary according to day of the week and month of the year. However, we removed the potential confounding effects of day of the week and month of the year, and we are unaware of remaining sources of bias in the analysis. On the other hand, our results probably underestimate the effect of a home defeat on supporters. Not all of the local health authority's male population will follow football, possibly diluting the observed effect. Some may follow other clubs, perhaps even outside the area, potentially further reducing the observed effect. The true relative risk of death from circulatory disease immediately after a home defeat among known supporters of that team is likely to be higher than the observed value for the whole population. Because of the limitations of available data, our results are unable to differentiate between match day deaths occurring before and after the kick off. Given that it is highly implausible to suppose that there is some other factor causing a raised death rate in association with a home defeat that operates before a match has taken place, this is likely to represent some further underestimate of the strength of association.

The reasons why one person with underlying coronary artery or cerebrovascular disease may suffer an acute episode while another does not are not clear. The daily, weekly, and seasonal variations in the onset of acute coronary syndromes and sudden cardiac death suggest that these are "triggered events". ${ }^{17}$ Trigger factors including unaccustomed physical exertion, emotional stress and external agents may act through haemodynamic effects, arrhythmias, hypertension, and hyperventilation, ${ }^{8}$ causing arterial plaques to become unstable and then disrupted. Emotional and psychological stresses that have been linked in this way with acute coronary syndromes and myocardial ischaemia include anger, sadness, frustration, and tension. ${ }^{6}$ Stroke rates are also known to be higher in association with mental stressors, particularly depression. ${ }^{7}$ Trigger factors have been estimated to play a causative part in $20 \%$ of cases of acute coronary syndrome. ${ }^{18}$

Our results do not identify the trigger factors that may have provoked the additional deaths observed. Losing at home may lead to anger, frustration, or depression among supporters, which are known to increase the risk of acute coronary and cerebrovascular events including sudden death. The Determinants of Myocardial Infarction Onset Study estimated the relative risk of acute myocardial infarction in the two hours after an outburst of anger to be 2.3 (reduced by aspirin to 1.4). ${ }^{19}$ Further study would be necessary to try to disentangle the effects of these potential trigger factors, and to shed light on why the association was found in men but not women.

It seems likely that the excess mortality that we have observed in association with a home defeat represents deaths brought forward that may otherwise have occurred later. However, there is no sign in our figures of a deficit in the days immediately after the peak, suggesting that this may be a comparatively long term effect. Our results therefore point to an area of potential public health improvement, as well as an opportunity to understand better the factors that may precipitate acute coronary and cerebrovascular disease.

Those with personal experience of the passion generated among fans devoted to a particular team may not be surprised by these results, having seen at first hand the effects of defeat. Others may question why disappointed fans do not simply switch to a more successful side. Although some do, to the true supporter this would be unthinkable. Pending further study, and given the evidence of its efficacy and relative safety, an appropriate preventive measure might be to recommend half an aspirin tablet to male supporters whose team has just been beaten at home. The more traditional supporter may prefer the use of alcohol to relieve stress on these occasions, but we would have to say that its effects on sudden cardiac death remain anecdotal by comparison with aspirin.

Our results also remind us that, to many, football is much more "a matter of life and death" than it is "only a game".

\section{ACKNOWLEDGEMENTS}

We thank Catherine Graham, Catherine Smith, and Jennifer Goodfellow and her team for their help in researching data and references. We also thank Ken Slater, Finance Director of Newcastle United FC, for assistance in collating football results.

\section{Contributors}

WK proposed the study. DWM refined the methodology and carried out the analysis. Both authors jointly wrote the report.

\section{Authors' affiliations}

W Kirkup, D W Merrick, NHS Northern and Yorkshire, Durham, UK

Funding: none.

Conflicts of interest: WK is a lifelong supporter and current season ticket holder of Newcastle United FC.

\section{REFERENCES}

1 Shankly W. www.shankly.com/lifeanddeath.htm (accessed 27 Jul 2001)

2 Deloitte and Touche. Annual review of football finance. August 2001. Manchester: Deloitte and Touche, 2001.

3 Hornby N. Fever pitch. London: Gollancz, 1992.

4 Shindler C. Manchester United ruined my life. London: Headline, 1998.

5 Witte DR, Bots ML, Hoes AW, et al. Cardiovascular mortality in Dutch men during 1996 European football championship: longitudinal population study. BM 2000;321:1552-4. 
6 Krantz DS, Sheps DS, Carney RM, et al. Effects of mental stress in patients with coronary artery disease. JAMA 2000;283:1800-2.

7 Sheps DS, Sheffield D. Depression, anxiety and the cardiovascular system: the cardiologist's perspective. J Clin Psychiatry 2001;62 (suppl 8): 12-16.

8 Tennant C, McLean L. The impact of emotions on coronary heart disease risk. J Cardiovasc Risk 2001;8:175-83.

9 Rollin J, Rollin G, eds. Rothmans Football Yearbook 2000-2001. London: Headline, 2000.

10 Rollin G, Rollin J, eds. Rothmans Football Yearbook 1999-2000. London: Headline, 1999.

11 Rollin G, Rollin J, eds. Rothmans Football Yearbook 1998-99. London: Headline, 1998.

12 Rollin G, ed. Rothmans Football Yearbook 1997-98. London: Headline, 1997.
13 Rollin J, ed. Rothmans Football Yearbook 1996-97. London: Headline, 1996.

14 Rollin J, ed. Rothmans Football Yearbook 1995-96. London: Headline, 1995.

15 Armitage P, Berry G. Statistical methods in medical research. 2nd edn. Oxford: Blackwell, 1987:110.

16 Frome EL. The analysis of rates using Poisson regression models. Biometrics 1983;39:665-74

17 Servoss SJ, Januzzi JL, Muller JE. Triggers of acute coronary syndromes. Prog Cardiovasc Dis 2002:44:369-80.

18 Willich SN. Circadian variation and triggering of cardiovascular events. Vascular Medicine 1999;4:41-9.

19 Mittleman MA, Maclure M, Sherwood JB, et al. Triggering of acute myocardial infarction onset by episodes of anger. Circulation 1995;92:1720-5.

\section{SPEAKER'S CORNER}

\section{About George W Bush's Iraq war}

can make no pretence to pacifism. It was out of conviction that, a mere 18 years old in my native South Africa, I volunteered for service in the second world war. And for the next five years I chose to serve in three successive services and on three successive fronts of the war. Nor have I ever regretted doing so, nor questioned that it was a right and necessary thing to do. That is to say, I believed then and believe now that there can be just and necessary wars, one of which was the war against Nazi Germany.

Nor, in the present instance in Iraq, do I dissent from the view that Saddam Hussein is a thoroughly wicked man. He perpetrated much evil among his people, waged war without any justification whatever, used proscribed chemical weapons (in his unprovoked war with Iran and on his own Kurdish subjects), and violated the surrender agreements about UN weapons inspections after the 1991 war he precipitated. An article in Science $e^{1}$ cogently assembles what has been discovered about the vast chemical weapons programme Iraq had going before and probably after the Gulf War.

None the less, as an American citizen (one admittedly transplanted, but one who has enjoyed here something of a charmed life), I must declare that I am appalled by the war in Iraq. The crucial issues are clear. No one will claim that either character disorder (which may well afflict Hussein) or the putative threat Hussein poses as dictator are legitimate grounds for preemptive war. As for allegations that could constitute real grounds subsequent to the Gulf War, two charges have been made. Firstly, as to the death and destruction wreaked by the attack of September 11,2001 on the World Trade Towers (towers that I looked on each day out of my office window): no substantive evidence has yet been produced about Hussein's connection with the Al Quaeda onslaught. Secondly, as to weapons of mass destruction (which do indeed raise health questions): since Saddam Hussein stalled the UN inspections instituted after the Gulf War ended, no new evidence has been produced about Iraq's current possession or production of such weapons (although, very likely, only because of successful evasion by the Iraqi regime). Worse, by short circuiting the search of the Security Council weapons team, the short fuse of Bush the Younger's ultimatum to Hussein precluded the possibility of their discovery. In doing so and bypassing the Security Council, a president elected with marginal legitimacy has gone far to undermine if not finally to destroy the world's best hope for an international instrument to maintain peace and law among nations, namely, an effective United Nations.

M Susser

Sergievsky Professor of Epidemiology Emeritus, Columbia University, New York, USA; mws2@columbia.edu

\section{Reference}

1 Stone R. Peering into the shadows. Iraq's bioweapons program. Science 2002;297:110-12 